\title{
CONSTITUTIVE MODEL OF STEEL FIBRE REINFORCED CONCRETE SUBJECTED TO HIGH TEMPERATURES
}

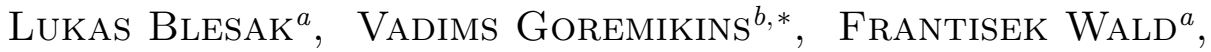 \\ TEREZA SAJDLOVA ${ }^{c}$ \\ ${ }^{a}$ Department of Steel and Timber Structures, Czech Technical University in Prague, Thákurova 7, Prague, Czech \\ Republic \\ ${ }^{b}$ Institute of Structural Engineering and Reconstruction, Riga Technical University, Azenes 16, Riga, Latvia \\ ${ }^{c}$ Department of Mechanics, Czech Technical University in Prague, Thákurova 7, Prague, Czech Republic \\ * corresponding author: goremikins@gmail.com
}

\begin{abstract}
Research on structural load-bearing systems exposed to elevated temperatures is an active topic in civil engineering. Carrying out a full-size experiment of a specimen exposed to fire is a challenging task considering not only the preparation labour but also the necessary costs. Therefore, such experiments are simulated using various software and computational models in order to predict the structural behaviour as exactly as possible. In this paper such a procedure, focusing on software simulation, is described in detail. The proposed constitutive model is based on the stress-strain curve and allows predicting SFRC material behaviour in bending at ambient and elevated temperature. SFRC material is represented by the initial linear behaviour, an instantaneous drop of stress after the initial crack occurs and its consequent specific ductility, which influences the overall modelled specimen behaviour under subjected loading. The model is calibrated with ATENA FEM software using experimental results.
\end{abstract}

KEYWORDS: SFRC material behaviour; four-point bending test; finite element modelling.

\section{INTRODUCTION}

Computational modelling of structural systems is a common practice in civil engineering, wherein the main purpose of software simulations is to predict, or better assume the behaviour of a structural system, structural element, etc., under particular conditions [1].

Various input data, such as proper geometry and boundary conditions, loading application and an appropriate material model are used to gain the most suitable results [2, 3]. This paper focuses on the last point - material model simulation. Steel fibre reinforced concrete (SFRC) is considered to be a homogenous material composed of a parent-concrete mixture and steel fibres. Various additives, such as polymer fibres (used in the SFRC mixture presented in this paper), are used to improve the SFRC material properties at elevated temperature [4].

One of the most advantageous properties of SFRC is its post-peak (or post-crack) behaviour [5]. The stressstrain curve of SFRC is characterized by its initial linear part, a consequent plastic part, a peak-area and finally its ductile post-peak area (see diagram in Figure 1). The typical post-peak behaviour makes SFRC a ductile material compared to plane concrete, which is brittle. Therefore, the best properties of concrete (in compression) and steel (in tension) are coupled together in a latter composite material. In comparison with compressive strength, uniaxial tensile strength of fibre concrete, especially at elevated temperature, is difficult to measure; therefore its tensile strength is usually defined either by a split-tension test or by fourpoint bending test following its flexural strength [6, 7]. Nevertheless, empirical formulas may be used to define the tensile strength of fibre concrete. Tensile resistance of steel fibres depends on several aspects, such as their type, diameter, end-shape, cross-section, material and anchoring to concrete [8]. Previous research has shown that the flexural strength of plain concrete (parent concrete) is increased by 1.5 to 3.0 times by adding steel fibres [9]. Naturally, this is highly affected by the facts listed above.

Different constitutive models for simulation of mechanical response of SFRC were introduced during the past decades. The constitutive models for SFRC can be classified into both macro- and meso-scale models (also called micro-scale in some papers) according to the scale in which they are defined [10. In macro-scale models the composite material is represented as a homogenous material with average properties. These models are based on different approaches for the continuum, such as the microplane model, smeared crack models, discrete crack models, elastoplastic models and damage models [10]. Meso-scale models allow considering both discontinuities in the cement matrix and the contribution of fibres across the interfaces of paste elements [11. A constitutive macro-scale model of SFRC subjected to high temperatures, calibrated with experimental results, is presented in this paper. 


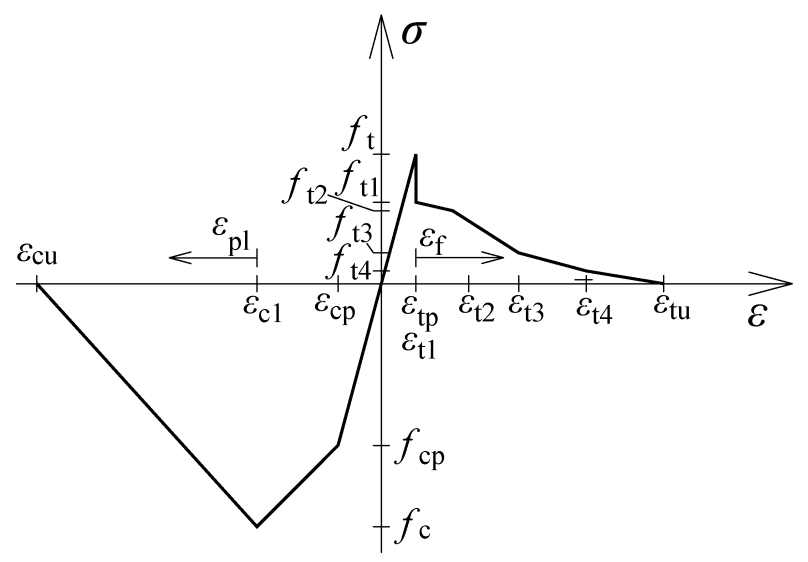

Figure 1. Constitutive law of the material defined by the stress-strain diagram development.

A material test of SFRC prisms at both ambient and elevated temperature and its simulation in the chosen software is presented in this paper, whilst the constitutive model for material behaviour is described in detail. A sensitivity study is also introduced. This study helps to understand how a FEM model is sensitive to the chosen input conditions and their modification. Based on the material tests performed at $20^{\circ} \mathrm{C}, 500^{\circ} \mathrm{C}$ and $600^{\circ} \mathrm{C}$, the most appropriate parameters of constitutive law for the FE material model of SFRC for elevated temperature up to $1100^{\circ} \mathrm{C}$ were defined. This paper is part of a complex research project, which includes material testing at elevated temperatures, structural testing at high temperatures [12, 13, and material and structural modelling. The results of structural modelling with a proposed material model are under preparation and will be presented in a forthcoming paper.

\section{DESCRIPTION OF MODEL}

\subsection{Constitutive LaWs FOR COMPRESSION BEHAVIOUR}

The stress-strain dependence was used for defining the behaviour of SFRC material. The compression part was defined according to EN 1992-1-2 [14] for regular concrete, adopting certain simplifications (see diagram in Figure 1):

$$
\sigma= \begin{cases}0, & \varepsilon<\varepsilon_{\mathrm{cu}}, \\ \frac{f_{c}\left(\varepsilon-\varepsilon_{\mathrm{cu}}\right)}{\varepsilon_{\mathrm{c} 1}-\varepsilon_{\mathrm{cu}}}, & \varepsilon_{\mathrm{cu}} \leq \varepsilon<\varepsilon_{\mathrm{c} 1}, \\ f_{c}+\frac{\left(f_{\mathrm{cp}}-f_{\mathrm{c}}\right)\left(\varepsilon-\varepsilon_{\mathrm{c} 1}\right)}{\varepsilon_{\mathrm{cp}}-\varepsilon_{\mathrm{c} 1}}, & \varepsilon_{\mathrm{c} 1} \leq \varepsilon<\varepsilon_{\mathrm{cp}}, \\ f_{\mathrm{cp}}+\frac{f_{\mathrm{cp}}\left(\varepsilon-\varepsilon_{\mathrm{cp}}\right)}{\varepsilon_{\mathrm{cp}}-\varepsilon_{\mathrm{c} 1}}, & \varepsilon_{\mathrm{cp}} \leq \varepsilon \leq 0 .\end{cases}
$$

As can be seen in the diagram in Figure 1, the compression part of a stress-strain curve consists of three linear parts: a proportional part, a plastic part and a post-peak part. The proportionality limit $f_{c p}$ is assumed to be $40 \%$ of the compressive strength $f_{c}$. The

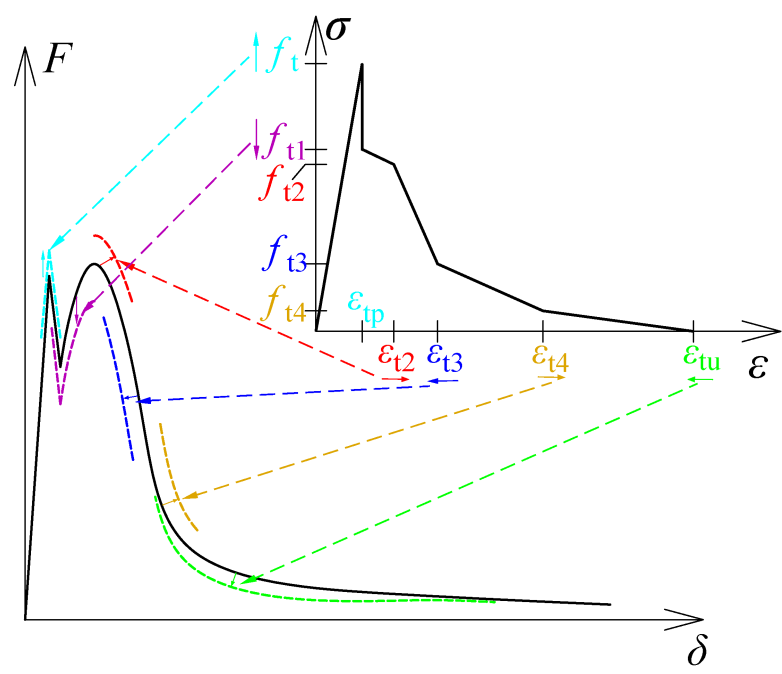

FiguRE 2. Influence of the tensile part of the stressstrain curve on force-displacement diagram development.

initial modulus of elasticity is calculated in compliance with 14 as follows: $E_{0}=3 f_{c} / 2 \varepsilon_{c 1}$.

\subsection{Constitutive LaWs FOR TENSION BEHAVIOUR}

The tensile part of a stress-strain curve is defined by six linear parts, the proportional part up to the tensile strength, the drop of stress after reaching the ultimate tensile strength and four parts that are used to define the post-peak material behaviour; (see diagrams in Figure 1):

$$
\sigma= \begin{cases}\frac{f_{\mathrm{t}} \varepsilon}{\varepsilon_{\mathrm{tp}}}, & \varepsilon<\varepsilon_{\mathrm{tp}}, \\ f_{\mathrm{t} 1}+\frac{\left(f_{\mathrm{t} 2}-f_{\mathrm{t} 1}\right)\left(\varepsilon-\varepsilon_{\mathrm{t} 1}\right)}{\varepsilon_{\mathrm{t} 2}-\varepsilon_{\mathrm{t} 1}}, & \varepsilon_{\mathrm{t} 1} \leq \varepsilon<\varepsilon_{\mathrm{t} 2}, \\ f_{\mathrm{t} 2}+\frac{\left(f_{\mathrm{t} 3}-f_{\mathrm{t} 2}\right)\left(\varepsilon-\varepsilon_{\mathrm{t} 2}\right)}{\varepsilon_{\mathrm{t} 3}-\varepsilon_{\mathrm{t} 2}}, & \varepsilon_{\mathrm{t} 2} \leq \varepsilon<\varepsilon_{\mathrm{t} 3}, \\ f_{\mathrm{t} 3}+\frac{\left(f_{\mathrm{t} 4}-f_{\mathrm{t} 3}\right)\left(\varepsilon-\varepsilon_{\mathrm{t} 3}\right)}{\varepsilon_{\mathrm{t} 4}-\varepsilon_{\mathrm{t} 3}}, & \varepsilon_{\mathrm{t} 3} \leq \varepsilon<\varepsilon_{\mathrm{t} 4}, \\ f_{\mathrm{t} 4}+\frac{\left.-f_{\mathrm{t} 4}\right)\left(\varepsilon-\varepsilon_{\mathrm{t} 4}\right)}{\varepsilon_{\mathrm{tu}}-\varepsilon_{\mathrm{t} 4}}, & \varepsilon_{\mathrm{t} 1} \leq \varepsilon<\varepsilon_{\mathrm{tu}}, \\ 0, & \varepsilon_{\mathrm{tu}}<\varepsilon .\end{cases}
$$

A drop in the measured force, after the first crack occurred, was observed in the experiment output data [15, 16]. The proposed material model therefore includes an instantaneous reduction in stress after the first crack occurs; see diagrams in Figure 1 and Figure 2, For a proper definition of SFRC constitutive law, various $2 \mathrm{D}$ and $3 \mathrm{D}$ models were proposed and consequently compared with the experiment output data. The constitutive laws, including the instantaneous reduction in stress in the tension part, led to the most appropriate and realistic results.

Certain parameters of a constitutive law, such as strains $\left(\varepsilon_{\mathrm{t} 2}, \varepsilon_{\mathrm{t} 3}, \varepsilon_{\mathrm{t} 4}, \varepsilon_{\mathrm{tu}}\right)$ and stress $\left(f_{\mathrm{t} 1}\right)$ of the tensile part of the diagram, should be determined by 

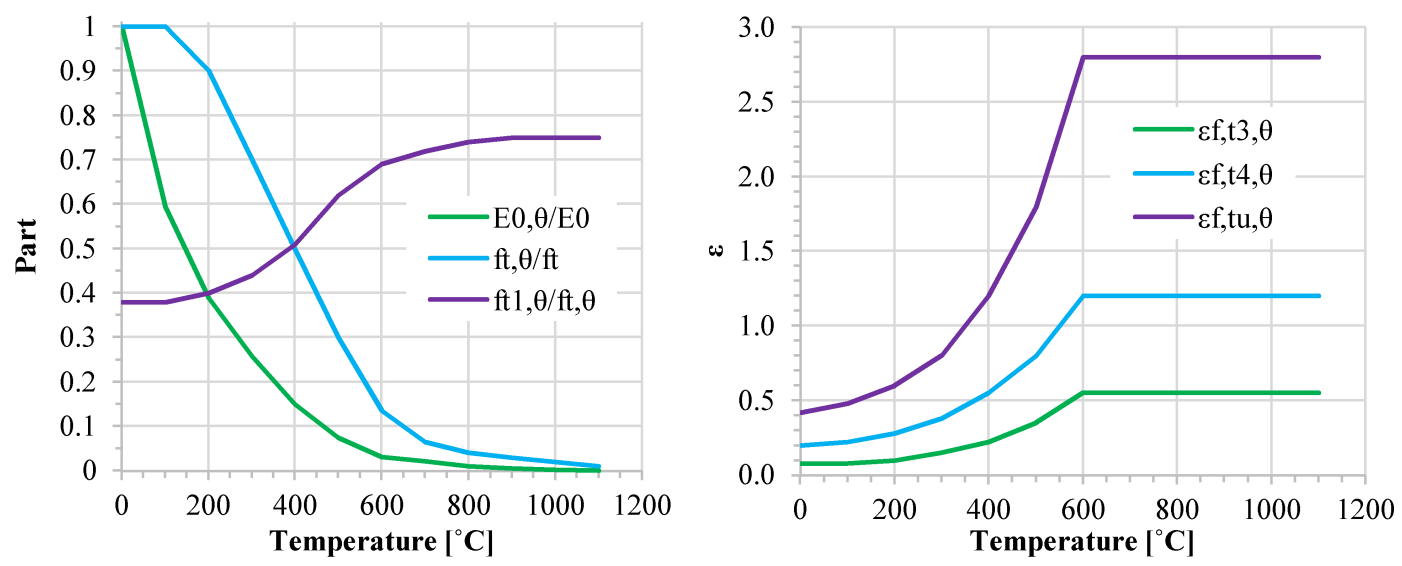

FiguRE 3. Variation of the parameters of the model depending on temperature.

an inverse analysis based on the experimental results. The values of other stress-points are set as follows: $f_{\mathrm{t} 2}=0.9 f_{\mathrm{t} 1}, f_{\mathrm{t} 3}=0.4 f_{\mathrm{t} 1}, f_{\mathrm{t} 4}=0.1 f_{\mathrm{t} 1}$. In order to increase the stability of the FE model, the stress/strength ratio should be set to a very small value at ultimate strain $\varepsilon_{\text {tu }}$, but not to zero (this paper assumes a value of 0.001). At the same time, zero stress/strength ratio should be set for a very large strain value, which could not be reached during modelling (this paper assumes a value of 4). The influence of the tensile part of the stress-strain curve on forcedisplacement diagram development is schematically shown in Figure 2

\subsection{Constitutive LaWs DEPENDING ON TEMPERATURE}

The constitutive model introduced in this paper behaves elastically until reaching the cracking point. As at elevated temperatures the real material is characterized by a certain plasticity before cracking, the initial modulus of elasticity was decreased in compliance with [14]. The constitutive law parameters depending on the temperature (Figure 3) were calibrated using the experimental results described in the subsequent sections. The shapes of dependences of the the parameters on temperature for the tensile behaviour were selected as similar to the compressive behaviour described in the Eurocodes [14].

\section{Material modelling in ATENA SCIENCE CODE SOFTWARE}

Either structural or material behaviour of any experimental test setup is normally defined by performing an experiment resulting in an appertaining stressstrain curve or load-displacement diagram development. There are several software packages offering a default material model definition normally based on input values such as the Young modulus, compression strength, tensile strength, Poisson ratio etc. These inputs are normalized and in most cases may be taken from appertaining standard, technical guidelines and others [14, 17.

In case of a SFRC, as presented herein, specific material behaviour, mainly in the post-peak part of a stress-strain diagram, is given by values which are neither provided by a relevant standard, nor easy to define experimentally. One such specific SFRC feature is fracture energy, marked as $G_{f}$ [18], which is defined as the amount of energy necessary to create one unit area of a crack [19. Fracture energy, being essential to define a proper SFRC behaviour, is a material property, and so it is not related to the size of a structural element. It is by no means easy to measure an exact value of fracture energy, and so it is normally determined by a consequent inverse analysis [17, 20].

Among several material models applied in the code of ATENA Science software (for details see [21, 22]) CC3DNonLinCementitious2User code was applied within this study. The tensile behaviour pattern of this material code is based on a stress-fracture strain definition, not on fracture energy as other material models in ATENA are, whilst the material model formulation is based on the strain decomposition into elastic, plastic and fracturing components [14. The general input data include the following: Young Modulus $E$, Poisson ratio $\nu$, tension strength $f_{\mathrm{t}}$, compression strength $f_{\mathrm{c}}$ - the applied data were taken from a split tension test output performed for the subjected SFRC mixture. Other data, such as thermal expansion or density, remained unchanged. It is essential to define a proper post-peak behaviour pattern to describe the real force-deflection diagram development, therefore the prior diagrams $\left(\sigma_{t} / f_{\mathrm{t}}\right)-\varepsilon_{\mathrm{f}}$ and $\left(\sigma_{c} / f_{\mathrm{c}}\right)-\varepsilon_{\mathrm{p} 1}$ were modified (see Figures 1 and 2).

The FEM model of the prism was produced by GID pre-processor software and Linear Hexahedron 8-node elements were considered in the displacement controlled simulation. Regarding the solver data, the Newton-Raphson method was considered.

$2 \mathrm{D}$ and 3D simulation each have their advantages and disadvantages, therefore both were applied within this study and the results were then further analysed. 


\begin{tabular}{lcccc}
\hline Title & Geometry & Middle element position & \multicolumn{2}{c}{ Scheme } \\
\hline Model 20A & double-symmetric & edge & z & \\
\hline Model 20B & real size & central axis & & \\
\hline Model 20C & real size & edge & \\
\hline
\end{tabular}

TABLE 1. Varied input conditions in the analysed models.

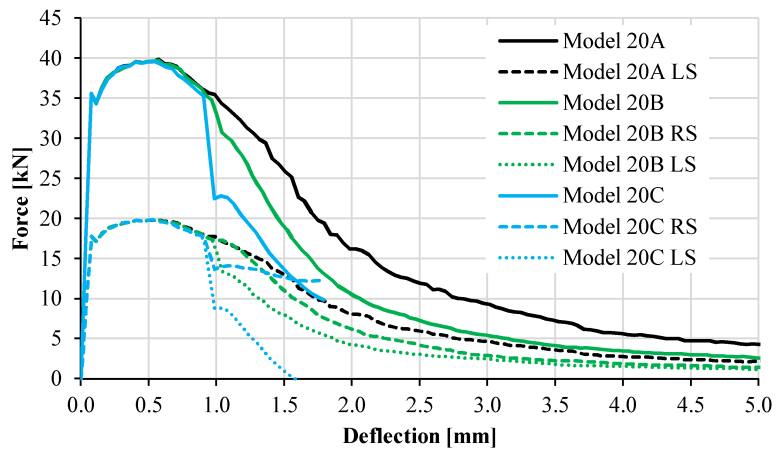

FiguRE 4. Force-deflection diagram for various material model compilations considering the right (RS) and left (LS) vertical reaction intensity.

A sensitivity study was performed and summarized for the material behaviour at ambient temperature. As a result of numerous models being used, a 3D FEM non-linear model appeared to be very sensitive to even small variations in the analysed input data, such as material properties, boundary conditions, element type and size and other.

The analysed material models are characterized by the input data introduced in Table 1

Besides the material behaviour observation, other factors, such as precision of the calculation, computing time, and needed modelling labour were taken into account when finding the most appropriate material model. 2D models are naturally convenient thanks to their short computing time. However, as observed in this study, it is not recommended to define the material properties in a $2 \mathrm{D}$ model and then apply a 3D model afterwards, due to transversal element deformation, tri-axial stress state condition and other phenomena present in $3 \mathrm{D}$ but absent in $2 \mathrm{D}$ models. The effects of the chosen input conditions on forcedeflection diagram development may be observed in Figure 4

Following "Model 20B - diagram", an example of asymmetry being influential over the achieved results can be observed. An $(x, y, z)$ support was applied to prevent the model from its spatial rotation. The vertical component of left and right reaction differ after reaching a certain value of vertical deflection due to the elements right above the support being deformed, see Figure 4. Model 20B RS and LS.

As observed, a non-symmetric system of supports

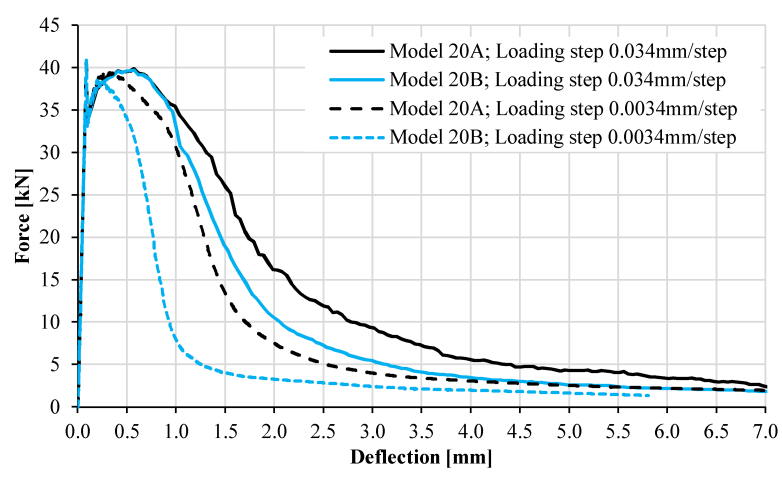

FiguRE 5. Force-deflection diagram and its variation based on different load-step size.

leads to a non-symmetric load distribution, to unequal values of vertical reactions and so to a misleading forcedeflection diagram pattern. A position of the initial crack occurrence was expected to be essential. As a crack is enabled to open only within an element - not in the elements' contact area (software feature), both models, with an element passing through the middle axis, with the elements' contact area passing through the middle axis, were compared (see Table 1. Models 20B and Model 20C, and Figure 4). The left and right reaction value variation is about twice as high for Model 20C compared to Model 20B. The asymmetric load distribution is caused not only by an asymmetric support system but also by a consequent asymmetric crack occurrence. The mirror element position with respect to the middle axis, Model 20C, enables the initial crack position to be located in either left or right side to the middle axis - not in the middle axis (see Table 2). Consequently, this phenomenon affects the initial cracks' width and the further crack evolution pattern.

The load-step size was analysed to verify its relevance not only in reaching the right position of peakpoint within a force-deflection diagram, but also to verify its influence over the cracks evolution - mainly the initial crack location. In Table 2 the initial crack occurrence in Model 20B, C and its modifications in connection to the load-step size are compared.

Further, various force-deflection diagram developments are depicted in Figure 5 . As observed, a loadstep size, the initial crack location, and the overall number of cracks in the modelled specimen essentially 


\begin{tabular}{|c|c|c|c|c|}
\hline \multirow[t]{2}{*}{$\begin{array}{l}\text { Applied } \\
\text { displacement }\end{array}$} & $\begin{array}{c}\text { Model 20C } \\
\text { Even number of } \\
\text { elements in the } \\
\text { middle part }\end{array}$ & $\begin{array}{l}\text { Model 20B } \\
\text { Odd number of } \\
\text { elements in the } \\
\text { middle part }\end{array}$ & $\begin{array}{l}\text { Model 20C } \\
\text { Even number of } \\
\text { elements in the } \\
\text { middle part }\end{array}$ & $\begin{array}{l}\text { Model 20B } \\
\text { Odd number of } \\
\text { elements in the } \\
\text { middle part }\end{array}$ \\
\hline & \multicolumn{2}{|c|}{ Loading step size: $0.034 \mathrm{~mm} / \mathrm{step}$} & \multicolumn{2}{|c|}{ Loading step size: $0.0034 \mathrm{~mm} / \mathrm{step}$} \\
\hline \multicolumn{5}{|l|}{$0.102 \mathrm{~mm}$} \\
\hline & $F=34.39 \mathrm{kN}$ & $F=34.35 \mathrm{kN}$ & $F=34.98 \mathrm{kN}$ & $F=35.02 \mathrm{kN}$ \\
\hline \multicolumn{5}{|l|}{$0.51 \mathrm{~mm}$} \\
\hline & $F=39.06 \mathrm{kN}$ & $F=39.43 \mathrm{kN}$ & $F=24.37 \mathrm{kN}$ & $F=23.37 \mathrm{kN}$ \\
\hline
\end{tabular}

TABLE 2. Initial crack position and its variation based on different input conditions.

influence the force-deflection diagram pattern. Literally, two cracks with a specific width each do not equal one crack with double the width, and therefore the number and size of cracks need to be considered carefully when defining the material properties.

\section{VAlidation of the MODEL}

In order to determine the required parameters of the introduced constitutive model, the experimental results of three test setups were considered: standard cube compressive test, standard cube split tensile test and four-point bending test. The SFRC material was prepared in concrete plants located in the towns Pisnice and Jindřichův Hradec (specimens from these plants will be marked with "P" and "H", respectively). Arcelor HE 75/50 hook-ended steel fibres with a content of $70 \mathrm{~kg} / \mathrm{m}^{3}$ were added to the parent concrete of strength class $45 / 55$. In order to improve the material properties of concrete in elevated temperatures, Krampe Harex DE 60/0.8 N polypropylene fibres were added, with a content of $1.5 \mathrm{~kg} / \mathrm{m}^{3}$. Cubes with dimensions of $150 \times 150 \times 150 \mathrm{~mm}$ were tested in compression and split tension tests at ambient temperature. An average strength in compression equal to 80.9 $\mathrm{MPa}$ was measured in six cubes and an average tensile strength equal to 7.4 MPa was measured in three cubes under lateral tension. Prisms with dimensions of $150 \times 150 \times 700 \mathrm{~mm}$ were tested at four-point bending test (see Figure 6) at ambient, $500{ }^{\circ} \mathrm{C}$ and $600^{\circ} \mathrm{C}$ temperature. Figure 7 shows a specimen in four point bending test after creation of the initial macro-crack. The four-point bending tests were performed on the specimens, which were heated up to $500^{\circ} \mathrm{C}$ and $600{ }^{\circ} \mathrm{C}$ by five electrical ceramic heaters

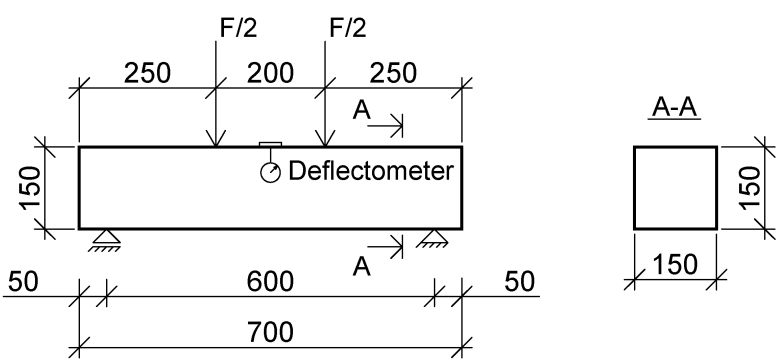

Figure 6. Scheme of four-point bending test setup.

attached to the specimens in the test machine (see Figure 7). A detailed description of the experiments is introduced in paper [13].

The parameters of the constitutive model were determined using an inverse analysis according to the experiments for temperatures of $20^{\circ} \mathrm{C}, 500{ }^{\circ} \mathrm{C}$ and $600^{\circ} \mathrm{C}$. The experimental results which differ by more than $20 \%$ from the middle value were not considered. The values of parameters of the constitutive law for the compression part of the stress-strain curve were used according to 14. Experimentally obtained and simulated load-deflection behaviour is depicted in Figures 8 10. Representative load-deflection curves are plotted to make the graphs transparent.

The constitutive law parameters for obtaining the force-deflection relationships depicted in Figures 810 are gathered in Table 3 As a matter of fact, such an SFRC mixture, as presented herein, is rather unique, primarily due to its high level of steel fibre content. Considering this fact, the available input data essential for defining the constitutive law parameters are very limited, both for ambient and elevated tempera- 

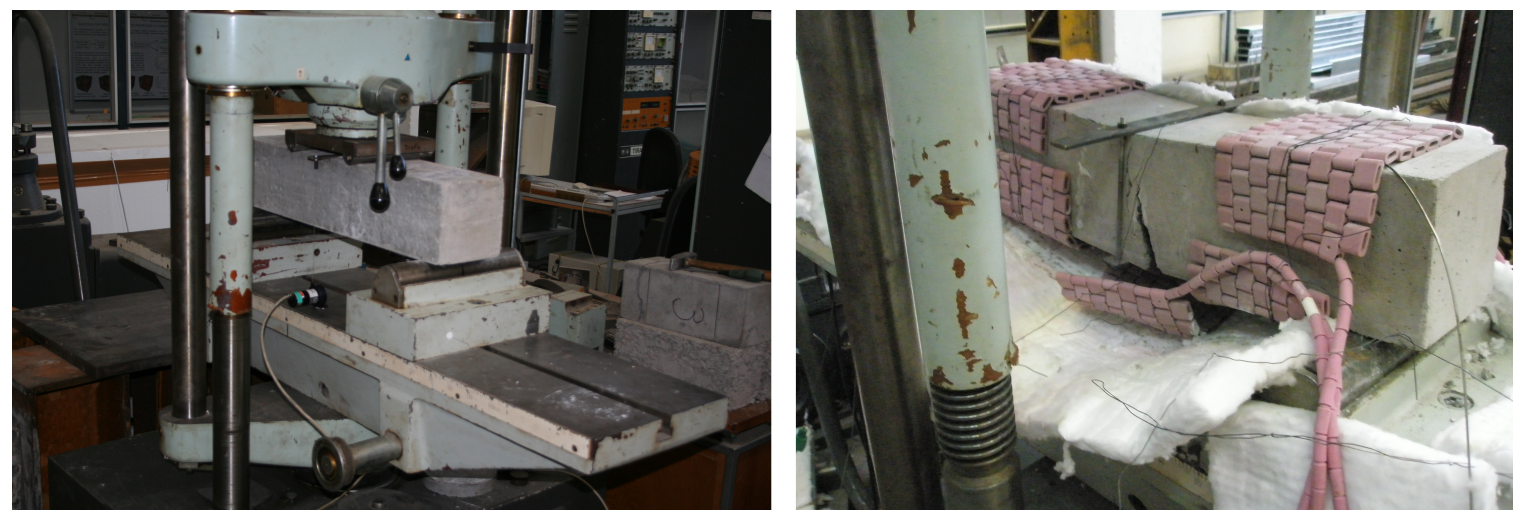

Figure 7. Prism during four-point bending test at ambient temperature (left), prism after four-point bending test at elevated temperature (right).

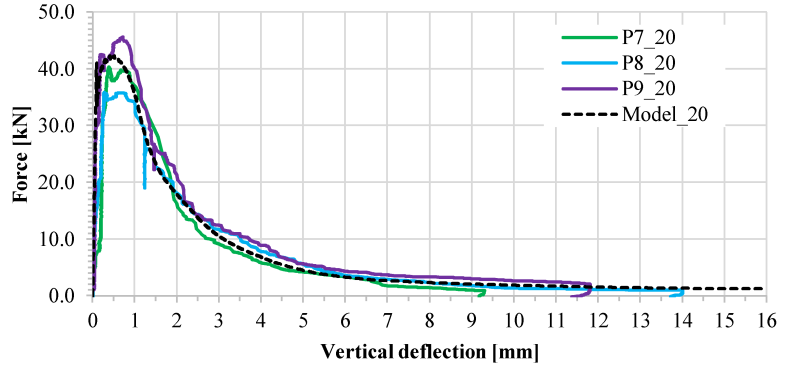

FiguRE 8. Experimentally obtained and calculated by the FE model force-deflection diagrams of samples at ambient temperature.

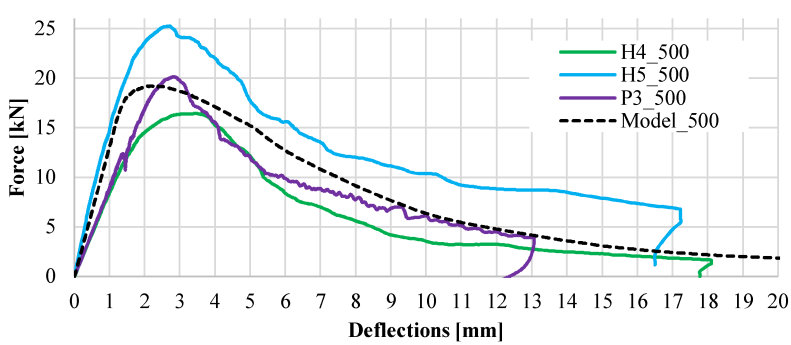

FigURE 9. Experimentally obtained and calculated by the model force-deflection diagrams of samples at a temperature of $500{ }^{\circ} \mathrm{C}$.

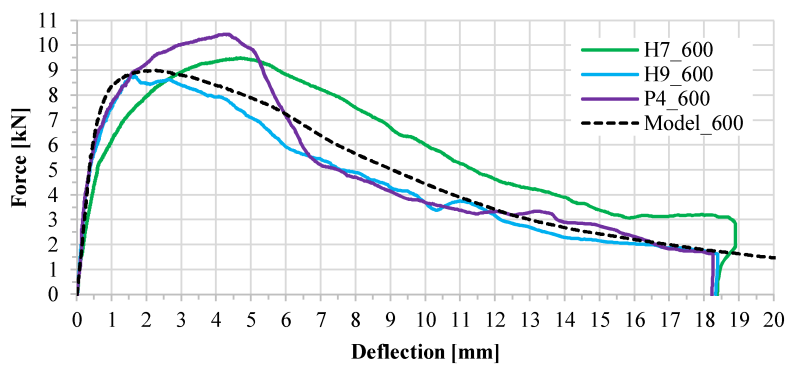

Figure 10. Experimentally obtained and calculated by the model force-deflection diagrams of samples at a temperature of $600^{\circ} \mathrm{C}$.

\begin{tabular}{lccc}
\hline Par. & $20^{\circ} \mathrm{C}$ & $500{ }^{\circ} \mathrm{C}$ & $600{ }^{\circ} \mathrm{C}$ \\
\hline$E_{0, \theta} / E_{\theta}$ & 1 & 0.0750 & 0.0315 \\
$f_{\mathrm{t}, \theta} / f_{\mathrm{t}}$ & 1 & 0.3 & 0.135 \\
$f_{\mathrm{t} 1, \theta} / f_{\mathrm{t}, \theta}$ & 0.380 & 0.620 & 0.690 \\
$\varepsilon_{\mathrm{ft} 2, \theta}$ & 0.035 & 0.035 & 0.035 \\
$\varepsilon_{\mathrm{ft} 3, \theta}$ & 0.077 & 0.350 & 0.550 \\
$\varepsilon_{\mathrm{ft} 4, \theta}$ & 0.200 & 0.800 & 1.200 \\
$\varepsilon_{\mathrm{ftu}, \theta}$ & 0.420 & 1.800 & 2.800 \\
\hline
\end{tabular}

TABle 3. Constitutive law parameters for obtaining the force-deflection relationships.

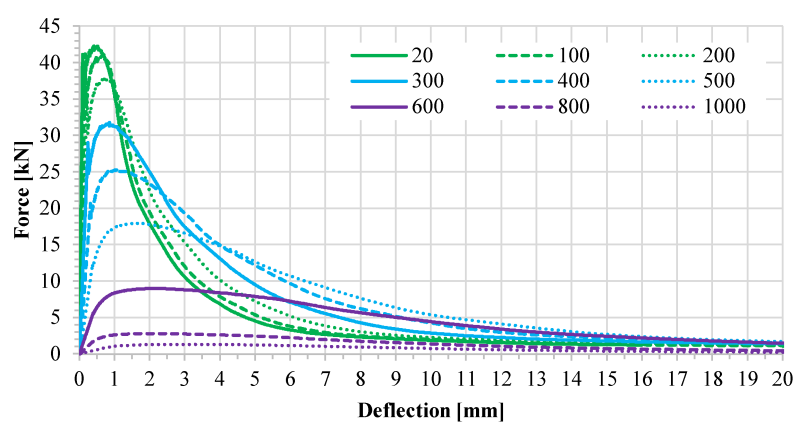

FiguRE 11. Force-deflection diagrams development for different temperatures calculated by the material model.

ture conditions. The inverse analysis applied within this research was performed manually, strictly following the recommendations listed by the ATENA software developer, introduced in the software manual documentation [23].

Figure 11 shows the results of calculations by the FE model force-deflection diagrams for different temperatures. Following the sensitivity study, the most appropriate way of modelling was used to define the particular force-deflection diagram developments for temperatures from $20^{\circ} \mathrm{C}$ up to $1000^{\circ} \mathrm{C}$.

\section{Conclusions}

The proposed constitutive model allows for the prediction of bending in SFRC material at ambient and 
elevated temperatures. Following the experimental results, various phenomena were observed in the SFRC material behaviour and so they were considered further.

Primarily, SFRC material is represented by the initial linear behaviour, an instantaneous reduction in stress after the initial crack occurs, and its consequent specific ductility, which influences the overall modelled specimen behaviour under subjected loading.

Having observed all the phenomena in the introduced analysis and considering the instantaneous reduction in stress after the initial crack occurs, it becomes apparent that defining the proper position of the initial crack location and applying a proper loadstep size is the most important parameters to be applied and controlled while modelling SFRC. The introduced material model is part of an overall research aiming to investigate structural systems made of SFRC in a further mechanical and thermal analysis. The ongoing research aims to implement satisfactory numerical and analytical computing procedures in the SFRC structural design to make SFRC material competitive with other structural materials when considering exposure to fire.

\section{ACKNOWLEDGEMENTS}

The work presented in this paper is supported by the Models of steel and fibre concrete composite columns exposed to fire project of the Grant Agency of the Czech Republic, GACR 15-19073S.

\section{REFERENCES}

[1] Gribniak, V., Cervenka, V., Kaklauskas, G.: Deflection prediction of reinforced concrete beams by design codes and computer simulation. Engineering Structures, 56, 2013, p. 2175-2186. DOI:10.1016/j.engstruct.2013.08.045

[2] Marciukaitis, G. et al.: A model for strength and strain analysis of steel fibre reinforced concrete. Journal of Civil Engineering and Management, 17(1), 2011, p. 137-145. DOI:10.3846/13923730.2011.561521

[3] Meskenas, A. et al.: Simplified technique for constitutive analysis of SFRC. Journal of Civil Engineering and Management, 20(3), 2014, p. 446-453. DOI:10.3846/13923730.2014.909882

[4] Fike, R., Kodur, V.: Enhancing the fire resistance of composite floor assemblies through the use of steel fiber reinforced concrete. Engineering Structures, 33(10), 2011, p. 2870-2878. DOI:10.1016/j.engstruct.2011.06.011

[5] Gribniak V. et al.: Deriving stress-strain relationships for steel fibre concrete in tension from tests of beams with ordinary reinforcement. Engineering Structures, 42, 2012, p. 387-395. DOI:10.1016/j.engstruct.2012.04.032

[6] Slowik, V. et al.: Computational aspects of inverse analyses for determining softening curves of concrete. Computer Methods in Applied Mechanics and Engineering, 195(52), 2006, p. 7223-7236. DOI:10.1016/j.cma.2005.04.021

[7] Salehian, H., Barros, J.A.O., Taheri M.: Evaluation of the influence of post-cracking response of steel fibre reinforced concrete (SFRC) on load carrying capacity of
SFRC panels. Construction and Building Materials, 73 , 2014, p. 289-304. DOI:10.1016/j.conbuildmat.2014.09.043

[8] Holschemacher, K., Mueller, T., Ribakov, Y.: Effect of steel fibres on mechanical properties of high-strength concrete. Materials and Design, 31(5), 2010, p. 2604-2615. DOI:10.1016/j.matdes.2009.11.025

[9] Elsaigh W.A.: Steel fibre reinforced concrete ground slabs. A comparative evaluation of plain and steel fibre reinforced concrete ground slabs. Master thesis.

Pretoria: University of Pretoria, 2001.

[10] Luccioni, B., et al.: A simple approach to model SFRC. Construction and Building Materials, 37, 2012, p. 111-124. DOI:10.1016/j.conbuildmat.2012.07.027

[11] Caggiano, A., Etse, G., Martinelli, E.: Zero-thickness interface model formulation for failure behavior of fiber-reinforced cementitious composites. Computers \& Structures, 98-99, 2012, p. 23-32. DOI:10.1016/j.compstruc.2012.01.013

[12] Caldová, E., et al.: Timber Steel Fibre-Reinforced Concrete Floor Slabs in Fire: Experimental and Numerical Modelling. Journal of Structural Engineering, 2014. DOI:10.1061/(ASCE)ST.1943-541X.0001182

[13] Bednář, J. et al.: Experiments on membrane action of composite floors with steel fibre reinforced concrete slab exposed to fire. Fire Safety Journal, 59, 2013, p. 111-121. DOI:10.1016/j.firesaf.2013.04.008

[14] EN 1992-1-2. Eurocode 2: Design of concrete structures - Part 1-2: General rules - Structural fire design. Brussels: European committee for standardization, 2004.

[15] Sukontasukkul, P., Pomchiengpin, W., Songpiriyakij, S.: Post-crack (or post-peak) flexural response and toughness of fibre reinforced concrete after exposure to high temperature. Construction and Building Materials, 24, 2010, p. 1967-1974. DOI:10.1016/j.conbuildmat.2010.04.003

[16] Caggiano, A. et al.: Fracture behaviour of concrete beams reinforced with mixed long/short steel fibres. Construction and Building Materials, 37, 2012, p. 832-840. DOI:10.1016/j.conbuildmat.2012.07.060

[17] Sajdlová, T.: Steel fibre reinforced concrete Material model parameters definition based on experimental results. Praha: CVUT, 2011.

[18] Červenka, V., Jendele, L., Červenka, J.: ATENA Program Documentation. Part 1. Theory. Prague: Červenka Consulting s.r.o., 2014.

[19] Barros, J.A.O., Sena Cruz, J.: Fracture energy of steel fibre reinforced concrete. Mechanics of Composite Materials and Structures, 8(1), 2001, p. 29-45. DOI:10.1080/10759410119428

[20] Löfgren, I., Stang, H., Olesen, J.F.: Fracture properties of FRC determined through inverse analysis of wedge splitting and three-point bending tests. Journal of Advanced Concrete Technology, 3(3), 2005, p. 423-434. DOI:10.3151/jact.3.423

[21] Pryl, D., Červenka, J.: ATENA Program Documentation. Part 11. Troubleshooting manual. Prague: Červenka Consulting s.r.o., 2014. 
[22] Červenka, V. et al.: ATENA Program

Documentation. Part 8. User's Manual for ATENA-GiD, Interface. Prague: Červenka Consulting s.r.o., 2014.

[23] Sajdlová, T.: ATENA Program Documentation. Part 4-7. ATENA Science - GiD FRC Tutorial. Prague:

Červenka Consulting s.r.o., 2016. 